Ensino, Saúde e Ambiente -V6 (2), pp. 20-32, ago. 2013

\title{
A AUTONOMIA PEDAGÓGICA DO ESTUDANTE: PERSPECTIVAS NA EDUCAÇÃO MÉDICA
}

\section{STUDENT AUTONOMY: PERSPECTIVES IN MEDICAL EDUCATION}

\author{
Maria Lúcia R. M. Smolka ${ }^{1}$, Andréia Patrícia Gomes², \\ Rosângela M. Mitre Cotta ${ }^{3}$, Luiz Alberto Santana ${ }^{5}$, Rodrigo Siqueira- \\ Batista $^{5}$ \\ ${ }^{1}$ Psicóloga do Núcleo de Apoio Psicopedagógico (NAPP), Centro Universitário Serra dos \\ Órgãos (UNIFESO), smolkam@uol.com.br \\ ${ }^{2}$ Professora Adjunta do Departamento de Medicina e Enfermagem, Universidade Federal de \\ Viçosa (UFV), andreia.gomes@ufv.br. \\ ${ }^{3}$ Professora Associada do Departamento de Nutrição e Saúde, Universidade Federal de \\ Viçosa (UFV), rmmitre@ufv.br. \\ ${ }^{4}$ Professor Adjunto do Departamento de Medicina e Enfermagem, Universidade Federal de \\ Viçosa (UFV), luizsantana@ufv.br. \\ ${ }^{5}$ Professor Adjunto do Departamento de Medicina e Enfermagem, Universidade Federal de \\ Viçosa (UFV); Docente permanente do Programa de Pós-graduação em Bioética, Ética \\ Aplicada e Saúde Coletiva, Universidade Federal do Rio de Janeiro (UFRJ), \\ rsbatista@ufv.br.
}

\section{RESUMO}

O presente artigo tem por escopo a apresentação dos resultados de uma investigação teórica acerca do papel da autonomia pedagógica discente no âmbito da educação médica.

PALAVRAS-CHAVE: Autonomia, Educação Médica; Ensino.

\section{ABSTRACT}

The scope of this paper is to present the results of a theoretical investigation about the role of student teaching autonomy in medical education.

KEYWORDS: Autonomy, Medical Education; Teaching.

\section{INTRODUÇÃO}

As sociedades democráticas contemporâneas têm reconhecido a importância da formação dos profissionais da saúde, no bojo dos hodiernos processos de valorização dos recursos humanos (PEREIRA \& ALMEIDA, 2005). Assim, o preparo dos estudantes para a prática de um cuidado humanizado à saúde - caracterizado pela alta qualidade e adequada resolutividade dos problemas -, se faz imprescindível. Torna-se, portanto, ainda mais relevante o exercício de reflexão pelos díspares atores implicados no ensino das profissões da saúde - estudantes, professores, trabalhadores, 
pesquisadores, gestores acadêmicos, gestores da saúde e controle social - a fim de implementar ações educacionais transformadoras nas escolas, as quais resultem em reais mudanças na esfera do trabalho (ALBUQUERQUE et al, 2008; MORAES \& MANZINI, 2006). Neste sentido pode-se ponderar que:

\begin{abstract}
[...] no campo da investigação do ensino das ciências da saúde tem-se questionado a utilidade dos conhecimentos e sua aplicabilidade social. Novas concepções de ensino e de aprendizagem estão sendo incorporadas no contexto escolar e na prática educativa. A valorização dos estudantes, enquanto sujeitos ativos na transformação das práticas de saúde, com compromisso social e agentes (re)construtores de seus conhecimentos, constitui a mais recente abordagem nesse campo. (MORAES \& MANZINI, 2006; p.125)
\end{abstract}

Tais princípios devem nortear a educação dos diferentes trabalhadores da área da saúde, a qual tem se pautado, ao longo do século no século XX, preponderantemente, nas recomendações do Relatório Flexner - publicado em 1910 -, o qual apresentou propostas de inclusão curricular das ciências básicas e das práticas hospitalares (MARANHÃO et al., 2012). Os resultados dessas proposições trouxeram a melhoria da qualidade técnica na formação - considerada muito ruim em inúmeras escolas médicas, à época da publicação do relatório -, mas, em contrapartida, acarretaram a supervalorização dos aspectos biológicos e a primazia do hospital como cenário para o ensino.

Atualmente, o panorama da saúde desnuda a inadequação do modelo - ainda hegemônico - de educação médica, focado na especialização precoce e no atendimento dirigido à doença - e não ao doente (MITRE et al., 2008). De fato, as dificuldades de acesso aos serviços de saúde, a não adesão terapêutica e o descontentamento dos pacientes com o cuidado ofertado - para mencionar alguns exemplos - são reflexos do modelo predominante. Diante desta perspectiva - e com a finalidade de minimizar os problemas de currículos que não atendam completamente às necessidades da formação dos médicos no Brasil - o Ministério da Educação, em suas Diretrizes Curriculares Nacionais do Curso de Graduação em Medicina - DCN (BRASIL, 2001) -, tem incentivado modelos de ensino médico pautados na integralidade do cuidado, nos quais os estudantes devem estar envolvidos, desde os primeiros períodos, em atividades curriculares ligadas à promoção, à prevenção, à reabilitação e à recuperação da saúde 
(MARANHÃO, et al., 2012; SILVA \& RIBEIRO, 2009). Além disso, é proposto que as metodologias de ensino-aprendizagem permitam a passagem de uma atitude discente passiva para uma postura ativa, a qual garanta a construção de um profissional que aprenda a aprender e que, diante de problemas tão complexos - como aqueles que se relacionem à saúde -, estejam capacitados a buscar soluções, tendo por base a capacidade de mobilização dos conhecimentos, a criatividade e a autonomia (GOMES et al., 2012).

Acredita-se, então, que os currículos construídos com base nas DCN sejam capazes de promover no estudante, de forma mais consistente, o desenvolvimento de uma postura autônoma frente à própria formação, na medida em que prevêm a aquisição, durante a graduação, de competências e habilidades gerais que se referem à tomada de decisão, comunicação, liderança, gerenciamento e educação permanente (BRASIL, 2001). Deste modo, facilita-se o amadurecimento cognitivo, comportamental e afetivo, no qual o exercício da autonomia, da criatividade, do trabalho em equipe e da não-completude da formação são considerados fundamentais para o êxito acadêmicoprofissional (SIQUEIRA et al., 2009).

Com base na consideração de que a construção da autonomia e a busca do conhecimento são passos essenciais para a formação de um profissional considerado competente do ponto de vista técnico e ético - em consonância com as DCN - o presente ensaio pretende discutir o papel da autonomia na formação médica. Para isso, optou-se por (1) resgatar-se brevemente o conceito de autonomia, em uma perspectiva histórica e filosófica, e, em seguida, (2) abordar o tema, no âmbito do ensino da medicina.

\section{MÉTODOS}

O trabalho constitui-se em uma investigação teórica, alicerçada na revisão da literatura - utilizando a Scientific Eletronic Library Online (SCIELO - www.scielo.br) -, tendo como elementos de busca as seguintes palavras (articuladas em estratégias):

(i) "autonomia" + "filosofia" + "educação" - primeira estratégia;

(ii) "autonomia" + "educação" + "médica" - segunda estratégia; e

(iii) "autonomia" + "ensino" + "medicina" - terceira estratégia. 
Ensino, Saúde e Ambiente -V6 (2), pp. 20-32, ago. 2013

A súmula do número de citações obtidas é apresentada no Quadro 1.

Quadro 1. Estratégias de busca utilizadas no SCIELO e número de citações obtidas.

\begin{tabular}{|l|c|}
\hline \multicolumn{1}{|c|}{ ESTRATÉGIA DE BUSCA* } & $\begin{array}{c}\text { NÚMERO DE CITAÇÕES } \\
\text { OBTIDAS }\end{array}$ \\
\hline $\begin{array}{l}\text { Estratégia } 1-\text { "autonomia" + "filosofia" + } \\
\text { "educação" }\end{array}$ & 13 \\
\hline $\begin{array}{l}\text { Estratégia } \\
\text { "médica" }\end{array}$ & 18 \\
\hline Estratégia 3 - "autonomia" + "ensino" + "medicina" & 17 \\
\hline
\end{tabular}

* A busca foi realizada até a data limite de 31/12/2012.

A partir da leitura das citações, procedeu-se a seleção dos artigos - 17 (dezessete) ao todo, utilizando como critério de escolha a pertinência para a abordagem histórica e filosófica do conceito de autonomia e para a delimitação de sua aplicabilidade no campo da educação médica -, realizou-se a análise crítica e a elaboração deste ensaio. Deve ser destacado que a busca bibliográfica foi complementada com referências de conhecimento prévio dos autores.

\section{RESULTADOS E DISCUSSÃO}

A partir da busca empreendida optou-se por elaborar a discussão, contemplando dois subtópicos - (1) O conceito de autonomia: aspectos históricos e filosóficos e (2) Autonomia e educação médica - os quais são apresentados a seguir.

\section{O conceito de autonomia: aspectos históricos e filosóficos}

A palavra autonomia tem sua origem em dois termos gregos - autos (próprio) nomos (lei ou regra) -, referindo-se à organização política helênica, na perspectiva de indicar as formas de governo autárquicas - cidades-estado - instituídas por volta do século VIII a. C. (CARDOSO, 1987). Ademais, pode-se buscar, igualmente, antecedentes históricos relativos ao conceito de autonomia no âmbito do Cristianismo: os homens foram criados, individualmente, à imagem e à semelhança divina, possuindo 
livre-arbítrio para seguir, ou não, os ensinamentos de Deus (SIQUEIRA-BATISTA \& SCHRAMM, 2008).

A despeito desta "preliminar" referência ao sujeito, é com o advento da Modernidade, que emerge o indivíduo, constituído e constituinte do eu pessoal, com capacidade para agir autonomamente nos âmbitos ético e epistemológico (MARCONDES, 2008; VALLE, 2008); ou seja, é a partir deste período que o conceito de autonomia passa a ser aplicado, definitivamente, ao homem/à mulher.

O pensamento de René Descartes - caracterizado pela centralidade da razão humana e pela valorização do indivíduo -, adquiriu papel central neste âmbito. De fato, para o filósofo do "se eu penso logo eu existo", é genuíno o espaço da liberdade humana, visto que "a principal perfeição do homem está em dispor de um livrearbítrio" (DESCARTES, 1952).

Entretanto, foram muitas as críticas ao modelo cartesiano - com repercussões na idéia de livre determinação - as quais provavelmente tiveram sua plena representação no pensamento de David Hume, filósofo escocês que procurou refutar as concepções de Descartes, reconhecendo as necessárias relações entre experiência e representação mental (HUME, 1999), ou seja, a constituição do sujeito não se dá apenas pelo pensamento racional, mas, igualmente, pelas sensações oriundas da experiência. Hume pode ser considerado o mais radical dos empiristas, assumindo uma posição filosófica cética; de fato, em sua perspectiva, o conhecimento não pode ser justificado por princípios fundados na razão e, ademais, não se pode ter nenhuma representação de nossa mente independente de nossa experiência (HUME, 1999; HUME, 2000).

Um ponto importante se refere à identidade pessoal / ao eu. Para o pensador escocês, a identidade pessoal nada mais é do que um feixe de percepções em um determinado momento e que varia na medida em que essas percepções mudam. Sendo assim, não se é agora o que se foi algum tempo atrás, nem mesmo o que se será mais tarde:

Há alguns filósofos que imaginam que estamos a todo momento conscientes de algo a que chamamos nosso 'eu' (Self) e que sentimos a sua existência contínua, tendo certeza, para além de qualquer evidência e demonstração, de sua perfeita identidade e simplicidade. [...] Mas o "eu" ou a pessoa não é uma impressão determinada, mas aquilo que se supõe que nossas várias impressões ou idéias têm como referência. Dor e prazer, tristeza e alegria, paixões e sensações sucedem-se umas às outras, e nunca existem todas ao mesmo tempo. Não pode ser, portanto, de nenhuma dessas impressões, nem 
de nenhuma outra, que a idéia de eu é derivada, e consequentemente esta ideia simplesmente não existe. (HUME, 1999; p.148)

As concepções de Hume promoveram ressonâncias no pensamento filosófico, principalmente nas ideias de Immanuel Kant, pensador que questiona os limites da metafísica - de acordo com a tradição Leibniz/Wollf (PASCAL, 2001) - à luz das críticas do "mais engenhoso dos céticos", cujos escritos o "despertaram" de um "sono dogmático" (KANT, 1966). A consequência é a proposição de novos modos para conceber as possibilidades e os limites do conhecimento. Segundo Kant, "todos os nossos conhecimentos provêm da experiência, mas segundo quadros e formas a priori que são próprias de nosso espírito" (KANT, 1966). Com efeito, o filósofo propõe o conceito de sujeito transcendental, o qual passa a ser mais uma forma estruturante de percepções, do que um conteúdo já composto de sua própria realidade (KANT, 1966). Ademais, do ponto de vista ético, delimita o sujeito moralmente autônomo, na Fundamentação da Metafísica dos Costumes (KANT, 1960), de modo que o conceito de autonomia ganha sua plena expressão em relação ao indivíduo, constituindo-se no embasamento da ação moral:

A moralidade é pois a relação das ações com a autonomia da vontade, isto é, com a legislação universal possível por meio das suas máximas. A ação que possa concordar com a autonomia da vontade é permitida; a que com ela não concorde é proibida. A vontade, cujas máximas concordem necessariamente com as leis da autonomia, é uma vontade santa, absolutamente boa. (KANT, 1966, p. 17)

O conceito de autonomia é, por conseguinte, grande devedor do trabalho de Kant e dos autores que dialogaram com este pensador - criticando ou ratificando suas proposições (CARVALHO, 2010; SIQUEIRA-BATISTA \& SCHRAMM, 2012) -, nos séculos XIX e XX. Deste modo, pode-se compreender melhor a autonomia, hoje, como:

[...] a capacidade de definir as suas próprias regras e limites, sem que estes precisem ser impostos por outro: significa que aquele agente é capaz de se auto-regular. Logo, na palavra autonomia estão implícitos, simultaneamente, a liberdade relativa do agente, que pode prescindir de um poder externo que o regule, e, a limitação, derivada necessariamente da relação com o mundo natural e social. (MOGILKA, 1999, p.59)

A idéia de autodeterminação do agente tem sido particularmente útil para se pensar não apenas as questões epistemológicas e éticas, mas também aquelas de 
natureza pedagógica (BARROSO, 2001; GARRISON, 1992), incluindo-se o bojo da educação médica, conforme será apresentado a seguir.

\section{Autonomia e formação médica}

Ao longo do processo educativo a autonomia emerge no âmago das interações intersubjetivas - especialmente quando está em jogo a concretização de projetos comuns -, visto que o ser humano não é isolado, mas, outrossim, um ser de relação. Portanto, acredita-se que nos processos pedagógicos centrados na autonomia do educando, o ambiente motivador e as relações interpessoais com colegas, com o curso e com os docentes são fundamentais para o efetivo desenvolvimento, no estudante, da capacidade de aprender a aprender, de trabalhar em equipe, de ouvir e de assumir um papel ativo e responsável pelo próprio aprendizado. Assim, alguns autores - como Barroso (2001), Garrison (1992), Guimarães \& Boruchovitch (2004), que tratam do tema da autonomia - referem-se à ideia de autogoverno, não em um sentido de independência, individualismo ou desapego, mas no âmbito da interdependência, sendo inconcebível imaginar uma situação na qual se pudesse agir de forma totalmente autônoma, uma vez que tal processo leva sempre em conta as influências externas e os movimentos de inter-relação com os outros (BARROSO, 2001; GARRISON, 1992; GUIMARÃES \& BORUCHOVITCH, 2004). Portanto, autonomia não é algo dado, mas sim o fruto de uma construção dialógica - com inextricável inscrição ético-política (SEMERARO, 2001) - e baseada nas relações entre as pessoas (MACEDO, 1991).

No âmbito do ensino superior, mais especificamente no contexto da formação médica, foram as chamadas metodologias ativas de ensino-aprendizagem (MAEA) especialmente a Aprendizagem Baseada em Problemas e a Problematização - que coligiram as discussões sobre a autonomia do educando. As raízes de tais debates podem ser buscadas nos construtivismos de Jean Piaget (2003), de Lev Vygotsky (2003) e de Paulo Freire (2006) - autores com referenciais teóricos próprios -, destacando-se como característica central as relações estabelecidas entre o sujeito e a realidade, de modo que o conhecimento se constrói pelas interações mútuas entre as referidas partes (PIAGET, 2003; VYGOTSKY, 2003; FREIRE, 2006; MACEDO, 1991). Os construtivismos buscam explicar o desenvolvimento da inteligência humana, valorizando as interações entre o ser humano e o meio, e as ideias de descobrir, 
inventar, redescobrir, criar, valorizando na mesma intensidade, o que se faz, como, e porque se faz, acompanhando os estágios da aprendizagem, vivenciados pelo discente, na aquisição de seus conhecimentos. Desse modo, pode-se dizer, em linhas gerais, que as distintas concepções construtivistas pressupõem o papel central do ambiente nos processos de ensino-aprendizagem, permitindo ao educando a construção do próprio saber. Com base nessas considerações, delimita-se a centralidade dos construtivismos como esteios teóricos das MAEA, as quais reconhecem a primazia da autonomia, conquistada pela relação do discente com o mundo e com seus pares, em um ambiente democrático, de liberdade, e de responsabilidade, pressupondo que, assim, o mesmo seja capaz de autogerenciar seu processo de formação (MEDEIROS et al., 2010; MITRE et al., 2008).

As MAEA - implementadas em alguns cursos de graduação em medicina alicerçadas em tais princípios teóricos, trazem a idéia de uma formação ampla que privilegia o preparo do "aprendiz" para o competente desempenho laboral como profissional e, integradamente, para a articulada participação social como cidadão (BAUMFELD et al., 2012). Tal cenário é bastante apropriado aos estudantes de medicina, na perspectiva de se permitir um ambiente acadêmico capaz de fomentar o desenvolvimento de graus crescentes de autonomia, ao longo de sua formação. Para Delors (2002), "este profissional-cidadão deve reunir em si o saber (conhecimentos teóricos), o saber fazer (técnicas e habilidades práticas) e o saber conviver (atitudes sociomorais conscientes), que, articulados no e pelo indivíduo, resultam no saber ser integral, autônomo e competente" (DELORS, 2002).

Assim sendo, ao longo da formação médica, o discente deve ser estimulado a estudar e se apropriar dos conteúdos considerados relevantes, se diferenciando do discente do currículo tradicional, o qual vivencia o ensino, muitas vezes, como mera transmissão de informações (SAKAI \& LIMA, 1996; VENTURELLI, 2003; p.232).

Nestes termos, a ABP, a problematização - e, igualmente, a aprendizagem por projetos - ganham destaque ao reconhecerem o papel central do educando na construção do conhecimento (CYRINO \& RIZZATO, 2004; GOMES et al., 2012; SAKAI \& LIMA, 1996; VENTURELLI, 2003). Ademais, acredita-se que as mudanças que ocorrem a partir da implementação de posturas mais democráticas nas relações docente-discente são capazes de acarretar transformações fundamentais - medidas pela 
responsabilização compartilhada, entre ambos -, as quais ampliam as possibilidades de uma construção mais responsável do conhecimento (FEUERWERKER, 2004).

Desta feita, o ensinar não se restringe à mera transmissão de conhecimentos, mas a criação de possibilidades para a produção do saber, para a qual uma das primeiras exigências é o rigor metodológico. $\mathrm{O}$ educador deve reforçar a capacidade crítica do educando auxiliando-o a tornar-se criativo, investigador, inquieto, rigorosamente curioso, humilde e persistente (FREIRE, 2006). Costa \& Siqueira-Batista (2004) ressaltam que o ato de ensinar exige respeito à autonomia e à dignidade de cada sujeito, sendo atitudes fundamentais de uma educação que efetivamente acredita no indivíduo como um ser capaz de construir a sua própria história. Assim, o papel do docente baseia-se no profundo respeito aos discentes em relação ao seu conhecimento, seu desenvolvimento e a sua individualidade dentro do contexto coletivo em que está inserido (FREIRE, 2006). Mitre e colaboradores (2008) ponderam, neste domínio, que:

[...] o respeito à autonomia só emerge no âmago de uma relação dialética na qual os atores envolvidos - docente e discente - se reconhecem mutuamente de modo a não haver docência sem discência, na medida em que as duas se explicam, e seus sujeitos, apesar das diferenças, não se reduzem à condição de objeto um do outro. (MITRE et al., 2008, p. 2135)

Ademais,

$\mathrm{O}$ respeito à autonomia e à dignidade de cada um é um imperativo ético e não um favor que podemos ou não conceder uns aos outros. Precisamente porque éticos podemos desrespeitar a rigorosidade da ética e resvalar para a sua negação, por isso é imprescindível deixar claro que a possibilidade de desvio ético não pode receber outra designação senão transgressão. (FREIRE, 2006, p. 66)

Desta feita, o docente, deve verdadeiramente acreditar na potencialidade do discente e ser capaz de cuidar da aprendizagem do aluno e da formação crítica e criativa do cidadão. Para tal, necessita ter humildade e consciência das próprias limitações em relação ao conhecimento (VIEIRA \& TAMOUSAUSKAS, 2013), percebendo o significativo ganho proveniente de sua relação com o estudante e, ainda, a amorosidade expressa pela atitude de compaixão (SIQUEIRA-BATISTA \& SCHRAMM, 2009), no sentido de acolhimento incondicional:

[...] ter sempre diante dos olhos - e dentro do coração - o respeito à autonomia parece ser o melhor modo para a compreensão, por parte do binômio docente/discente, do processo de produção, expressão e apreensão 
Ensino, Saúde e Ambiente -V6 (2), pp. 20-32, ago. 2013

do conhecimento, dentro de uma perspectiva de transformação da realidade, afinal, conhecer é transformar. (Mitre et al., 2008, p. 2136).

Para além destas conjecturas epistemológicas, no que diz respeito ao alcance dos objetivos propostos nas MAEA, diversos autores que tratam do tema autonomia nos cenários de aprendizagem chamam a atenção para a importância da inter-relação com os pares, para que o aprendiz possa assumir um determinado (auto)domínio sobre sua aprendizagem (FREIRE, 2006; GOMES et al., 2012; MOURA, 1999; VENTURELLI, 2003).

Ressalta-se neste aspecto a imprescindibilidade da relação dialética do par docente-discente, na qual um não existe sem o outro, pois ambos se explicam e se complementam, não sendo um apenas "objeto" do outro (MITRE et al., 2008). É a partir desta relação que emerge o respeito à autonomia do discente, alicerce para uma educação que leva em consideração o indivíduo como um ser que constrói a sua própria história, lidando com seus limites e os limites do outro, enfrentando-os e superando-os, promovendo assim uma verdadeira transformação da educação e de si mesmo.

\section{CONSIDERAÇÕES FINAIS}

As ponderações elaboradas ao longo do presente ensaio pretendem contribuir, mesmo que preliminarmente, às reflexões a respeito do papel da autonomia no desenvolvimento dos estudantes de medicina, mormente aqueles que vivenciam currículos baseados nas MAEA. Nos mais variados cenários de discussão, as concepções de autonomia têm apresentado dificuldades referentes à sua conceituação bem como às consistentes críticas dirigidas à ideia de autodeterminação (BRAZ, 1999; CARVALHO, 2010; SIQUEIRA-BATISTA \& BATISTA, 2009), as quais fogem ao escopo da presente abordagem -, o que não é diferente em relação ao seu desenvolvimento no contexto educacional do ensino superior.

Sabendo, então, que os estudantes que ingressam em um curso de medicina estão habituados ao paradigma tradicional dominante - o qual pressupõe o ensinoaprendizagem centrado no professor -, acredita-se que as MAEA possam redirecionar a educação médica para a formação de um sujeito - profissional e cidadão - dotado da capacidade de agir com autonomia no mundo da vida e no mundo do trabalho. Para 
Ensino, Saúde e Ambiente -V6 (2), pp.20-32, ago. 2013

isso, considera-se que o desenvolvimento da postura autônoma frente à própria formação é, efetivamente, uma fundamental característica para o futuro médico.

\section{REFERÊNCIAS}

ALBUQUERQUE, V. S., TANJI, S., GOMES, A. P., SIQUEIRA-BATISTA, R. Pressupostos da construção de um novo currículo para a Enfermagem. Rev Bras Enf. UFPE. 2008;2:397-403.

BARROSO, J. O reforço da autonomia das escolas e a flexibilização da gestão escolar em Portugal. In: Ferreira, N. S. C. Gestão Democrática da educação: atuais tendências, novos desafios. São Paulo: Cortez; 2001.

BAUMFELD, T., SÁ, R. B., SANTOS, D. F. A., MONTEIRO, O. M., FERREIRA, M. B., SILVA, E. M. V., RAYMUNDO, M. A. I., QUEIROZ, A. M., BONOLO, P. F. Autonomia do cuidado: interlocução afetivo-sexual com adolescentes no PETSaúde. Rev Bras Educ Med 2012; 36(1):71-80.

BRASIL. Ministério da Educação. Conselho Nacional de Educação, Câmara de Educação Superior. Diretrizes Curriculares Nacionais do Curso de Graduação em Medicina. Resolução CNE/CES Nº 4, Brasília, 7 de Novembro, 1-6, 2001.

BRAZ, M. Autonomia: onde mora a vontade livre? In: Carneiro F. A moralidade dos atos científicos. Rio de Janeiro: FIOCRUZ; 1999.

CARDOSO, C. A cidade-estado antiga. São Paulo: Ática; 1987.

CARVALHO, J. S. A liberdade educa ou a educação liberta? Uma crítica das pedagogias da autonomia à luz do pensamento de Hannah Arendt. Educ Pesqui 2010; 36(3):839-851.

COSTA, C. R. B. S. F., SIQUEIRA-BATISTA, R. As teorias do desenvolvimento moral e o ensino médico: uma reflexão pedagógica centrada na autonomia do educando. Rev Bras Educ Med. 2004;28(3):242-250.

CYRINO, E. G., RIZZATO, A. B. P. Contribuição à mudança curricular na graduação da Faculdade de Medicina de Botucatu. Rev Bras Saude Mater Infant 2004; 4(1): 59-69.

DELORS, J. Educação: um tesouro a descobrir. 9. ed. São Paulo: Cortez; Brasília, DF: MEC, UNESCO, 2002.

DESCARTES, R. Les príncipes de la philosophie. Paris: Gallimard; 1952.

FEUERWERKER, L. C. M. Gestão dos processos de mudança na graduação em medicina. In: Marins, JJN, Rego S, Lampert JB, Araújo JGC. orgs. Educação médica em transformação: instrumentos para a construção de novas realidades. São Paulo: Hucitec; 2004. p.17-39. 
Ensino, Saúde e Ambiente -V6 (2), pp. 20-32, ago. 2013

FREIRE, P. Pedagogia da autonomia: saberes necessários à prática educativa. $33^{\mathrm{a}}$ ed. São Paulo: Paz e Terra; 2006.

GARRISON, D. Critical thinking and self-directed learning in adult education. Adult Education Quartely.1992;2:102-116.

GOMES, A. P., BITTENCOURT-COSTA, J. R., JUNQUEIRA, T. S., ARCURI, M. B., SIQUEIRA-BATISTA, R. Atenção primária à saúde e formação médica: entre episteme e práxis. Rev Bras Edu Méd 2012; 36: 541-549.

GUIMARÃES, S. R., BORUCHOVITCH, E. O estilo motivacional do professor e a motivação intrínseca dos estudantes: uma perspectiva da teoria da autodeterminação. Psicol Reflexão e Crítica. 2004;17(2):143-150.

HUME, D. Investigação sobre o entendimento humano. São Paulo: Editora da UNESP; 1999.

HUME, D. Tratado da natureza humana. São Paulo: Editora da UNESP; 2000.

KANT, I. Crítica da razão pura. Rio de Janeiro: Edições de Ouro; 1966.

KANT, I. Fundamentação da metafísica dos costumes. Lisboa: Edições 70; 1960.

MACEDO, B. Projecto educativo de escola: do porquê construí-lo à génese da construção. Inovação 1991; 4(2-3):127-139.

MARANHAO, E. A.; GOMES, A. P.; SIQUEIRA-BATISTA, R. O que mudou na educação médica a partir das Diretrizes Curriculares Nacionais: sob os olhares do Jano de Duas Faces. In: Streit, D. S.; Barbosa Neto, F.; Lampert, J. B.; Lemos, J. M. C.; Batista, N. A. 10 anos de Diretrizes Curriculares Nacionais. Rio de Janeiro: ABEM, 2012, v. , p. 59-91.

MARCONDES, D. Iniciação à História da filosofia: dos pré-socráticos a Wittgenstein. Rio de Janeiro: Jorge Zahar; 2008.

MEDEIROS, A. C., PEREIRA, Q. L. C., SIQUEIRA, H. C. H, CECAGNO, D., MORAES, C. L. Gestão participativa na educação permanente em saúde: olhar das enfermeiras. Rev Bras Enf. 2010; 63(1):38-42.

MITRE, S. M., SIQUEIRA-BATISTA, R., GIRARDI-DE-MENDONÇA, J. M., MORAIS-PINTO, N.M., MEIRELLES, C. A. B., PINTO-PORTO, C., MOREIRA, T., HOFFMANN, L. M. A. Metodologias ativas de ensino-apredizagem na formação profissional em saúde: debates atuais. Ciênc \& Saúde Colet. 2008;13(2):2133-2144.

MOGILKA, M. Autonomia e formação humana em situações pedagógicas: um difícil percurso. Educ Pesq. 1999; 25(2):57-68.

MORAES, M. A. A.; MANZINI, E. J. Concepções sobre a aprendizagem baseada em problemas: um estudo de caso na FAMEMA. Rev Bras Educ Med. 2006;30(3):125-135 
MOURA, R. O Conceito de autonomia de escola: algumas reflexões. Educare/Educere. 1999; 7: 85-94.

PASCAL, G. O pensamento de Kant. $7^{\text {a }}$ ed. Petrópolis: Vozes; 2001.

PEREIRA, O. P., ALMEIDA, T. M. C. A formação médica segundo uma pedagogia de resistência. Interface 2005;19(16):69-79.

PIAGET, J. Seis estudos de psicologia. 24a ad. Rio de Janeiro: Forense; 2003.

PINTO, C. Escola e autonomia. In: Dias, A.; Silva, A.; Pinto, C.; Hapetian, I. A autonomia das escolas: um desafio. Lisboa: Texto Editora; 1998.

SAKAI, M. H., LIMA, G. Z. PBL: uma visão geral do método. Olho mágico. 1996;2(56): 24-36.

SEMERARO, G. Anotações para uma teoria do conhecimento em Gramsci. Rev Bras Educ 2001; 16:95-104.

SILVA, R. P.; RIBEIRO, V. M. B. Inovação curricular nos cursos de graduação em Medicina: o ensino da bioética como uma possibilidade. Rev Bras Educ Med. 2009;33(1):134-143.

SIQUEIRA, J. R. M., BATISTA, R. S., MORCH, M. B., SIQUEIRA-BATISTA, R. Aprendizagem Baseada em Problemas: o que os médicos podem ensinar para os contadores. Contab Vist Rev. 2009; 20:101-125.

SIQUEIRA-BATISTA, R., BATISTA, R. S. Os anéis da serpente: a aprendizagem baseada em problemas $\mathrm{e}$ as sociedades de controle. Ciênc \& Saúde Colet. 2009;14:1183-1192.

SIQUEIRA-BATISTA, R., SCHRAMM, F. R. A bioética da proteção e a compaixão laica: o debate moral sobre a eutanásia. Ciênc \& Saúde Colet. 2009;14(4):1241-1250.

SIQUEIRA-BATISTA, R., SCHRAMM, F. R. Bioética e neurociências: variações sobre o tema dos paradoxos da autonomia. In: Esperidião Antonio V. Neurociências: diálogos e interseções. Rio de Janeiro: Rubio, 2012, p. 473-487.

SIQUEIRA-BATISTA, R., SCHRAMM, R. A eutanásia e os paradoxos da autonomia. Ciênc \& Saúde Colet. 2008;13:207-221.

VALLE, L. Castoriadis: uma filosofia para a educação. Educ Soc 2008; 29(103): 493513.

VENTURELLI, J. Educación médica: nuevos enfoques, metas y métodos. 2. ed. Washington, DC: Organización Panamericana de la Salud/Organización Mundial de la Salud; 2003. 
Ensino, Saúde e Ambiente -V6 (2), pp.20-32, ago. 2013

VIEIRA, J. E., TAMOUSAUSKAS, M. R. G. Avaliação das resistências de docentes a propostas de renovações em currículos de graduação em medicina. Rev Bras Educ Med 2013; 37(1):32-38.

VYGOTSKY, L. S. Psicologia Pedagógica. Porto Alegre: Artmed; 2003. 